\title{
Gluconate Metabolism Is Required for Virulence of the Soft-Rot Pathogen Pectobacterium carotovorum
}

\author{
Beth Mole, ${ }^{1,2}$ Sohrab Habibi, ${ }^{3}$ Jeffery L. Dangl, ${ }^{1,2,4,5}$ and Sarah R. Grant ${ }^{1,4}$ \\ ${ }^{1}$ Department of Biology, ${ }^{2}$ Department of Microbiology and Immunology, ${ }^{3}$ Director, Mass Spectrometry Facility, \\ Department of Chemistry, ${ }^{4}$ Curriculum in Genetics and Molecular Biology, and ${ }^{5}$ Carolina Center for Genome Sciences, \\ University of North Carolina, Chapel Hill 27599, U.S.A.
}

Submitted 19 March 2010. Accepted 27 June 2010.

\begin{abstract}
Pectobacterium carotovorum is a ubiquitous soft rot pathogen that uses global virulence regulators to coordinate pathogenesis in response to undefined environmental conditions. We characterize an operon in $P$. carotovorum required for gluconate metabolism and virulence. The operon contains four genes that are highly conserved among proteobacteria (initially annotated ygbJKLM), one of which was misassigned as a type III secreted effector, ( $y g b K$, originally known as hopAN1). A mutant with a deletion-insertion within this operon is unable to metabolize gluconate, a precursor for the pentose phosphate pathway. The mutant exhibits attenuated growth on the leaves of its host of isolation, potato, and those of Arabidopsis thaliana. Notably, the mutant hypermacerates potato tubers and is deficient in motility. Global virulence regulators that are responsive to cell wall pectin breakdown products and other undefined environmental signals, KdgR and FlhD, respectively, are misregulated in the mutant. The alteration of virulence mediated via changes in transcription of known global virulence regulators in our $y g b J-M$ operon mutant suggests a role for host-derived catabolic intermediates in $P$. carotovorum pathogenesis. Thus, we rename this operon in $P$. carotovorum vgu $\mathrm{ABCD}$ for virulence and gluconate metabolism.
\end{abstract}

Pectobacterium carotovorum subsp. carotovorum is a plantassociated Enterobacteriaceae family member found worldwide in surface waters, soil, carrier invertebrates, as well as plant hosts (Molina 1974; Harrison 1977; McCarter-Zorner 1984, 1985). P. carotovorum can infect a range of plants to cause softrot disease and is responsible for significant economic losses in potato production each year. The strain $P$. carotovorum subsp. carotovorum WPP14, which we discuss here, was isolated from the irrigation pond of a Wisconsin state potato farm suffering from a rot outbreak after a hailstorm (Yap et al. 2004). P. carotovorum can infect a host plant by multiple routes and can elicit disease on leaves and stems as well as in tubers. Soft-rot outbreaks are generally triggered by environmental factors such as rain or hot weather and can strike during tuber storage, leading to total crop loss (Charkowski 2009).

The nucleotide sequences of the $v g u A B C D$ operon consists of the following nucleotides from GenBank accession ABVY01000079: vguA, 11,054 to 11,$968 ; v g u B, 11,965$ to 13,$239 ; v g u C, 13,236$ to 13,$892 ; v g u D, 13,914$ to 14,708 .

Corresponding author: S. R. Grant; E-mail: sgrant@email.unc.edu

* The $e$-Xtra logo stands for "electronic extra" and indicates that two supplementary figures and two supplementary tables are published online.
Pectobacterium spp. are often described as brute-force pathogens because their virulence strategy relies heavily on plant cell wall-degrading enzymes (PCWDE), which are secreted via a type II secretion system (T2SS) (Allen et al. 1989; Matsumoto et al. 2003; Lagaert et al. 2009). Cellulases, pectate lyases, and polygalacturonase are responsible for the characteristic rotting symptoms of infection by $P$. carotovorum and, consequently, its necrotrophic life-history (Murata et al. 1994). However, P. carotovorum uses an array of virulence determinants in addition to the T2SS (Toth and Birch 2005), including antibiotics, metalloproteases, adhesins, and a type III secretion system (T3SS), which are all controlled by a wellstudied network of regulators (Pirhonen et al. 1993; Cui et al. 1999; Flego et al. 2000; Toth and Birch 2005; Laasik et al. 2006; Barnard and Salmond 2007; Liu et al. 2008; Charkowski 2009). For example, at least three regulators manipulate the production of PCWDE, KdgR, HexA, and RsmA.

$\mathrm{KdgR}$ is a repressor, conserved in enterobacteria that blocks transcription of PCWDE genes in the absence of pectin-breakdown products (Liu et al. 1999; Rodionov et al. 2004). KdgR is a rare example where we understand how known extracellular signals directly influence the characterized signaling cascades in a related species, Dickeya dadantii (formerly Erwinia chrysanthemi) (Hugouvieux-Cotte-Pattat and Robert-Baudouy 1987). The actions of KdgR feed into the Rsm post-transcriptional regulation system in D. dadantii (Nasser et al. 1997), which is a central component of virulence regulation modules in P. carotovurom (Liu et al. 1998; Baker et al. 2002). KdgR function regulates the Rsm post-transcriptional regulation system (Nasser et al. 1997), which is a central component of virulence regulation modules in $P$. carotovurom (Liu et al. 1998; Baker et al. 2002). KdgR negatively regulates $r s m B$, a functional RNA that sequesters RsmA. RsmA binds to and regulates translation of target transcripts (Mukherjee et al. 1998), including PCWDE gene transcripts. In the presence of pectin breakdown products, KdgR derepresses PCWDE genes and $r s m B$ expression, leading to PCWDE transcription and sequestration of RsmA by $r s m B$ and consequent PCWDE translation. However, the Rsm system is influenced by multiple regulators, including the acyl homoserine lactone receptor ExpR (Cui et al. 2005, 2006), and regulates multiple virulence factors in addition to the PCWDE (Sjoblom et al. 2006), including the T3SS and toxins (Chatterjee et al. 1995; Cui et al. 1995). Thus, a complex network of concerted and antagonistic regulators determines virulence expression in the variety of environments and host tissues in which $P$. carotovorum is found.

Environmental conditions are likely to be continuously monitored by $P$. carotovorum during the transition from soil or surface water to the leaf, stem, or tuber of a host plant and subse- 
quent progress through the stages of infection (Whitehead et al. 2002; Lazdunski et al. 2004; Yang et al. 2008; Li et al. 2009). Although $\mathrm{KdgR}$ is responsive to pectin-breakdown products, other virulence regulators that feed into the Rsm system are responsive to as yet unknown environmental cues. The FlhDC hexomer, another key virulence regulator, acts downstream of environmental signals and upstream of the Rsm system (Cui et al. 2008). Considered the master regulator of motility, FlhDC interacts genetically with multiple virulence regulators, including the two-component system, GacA/S, and a LysR-like transcriptional regulator, HexA (Harris et al. 1998; Mukherjee et
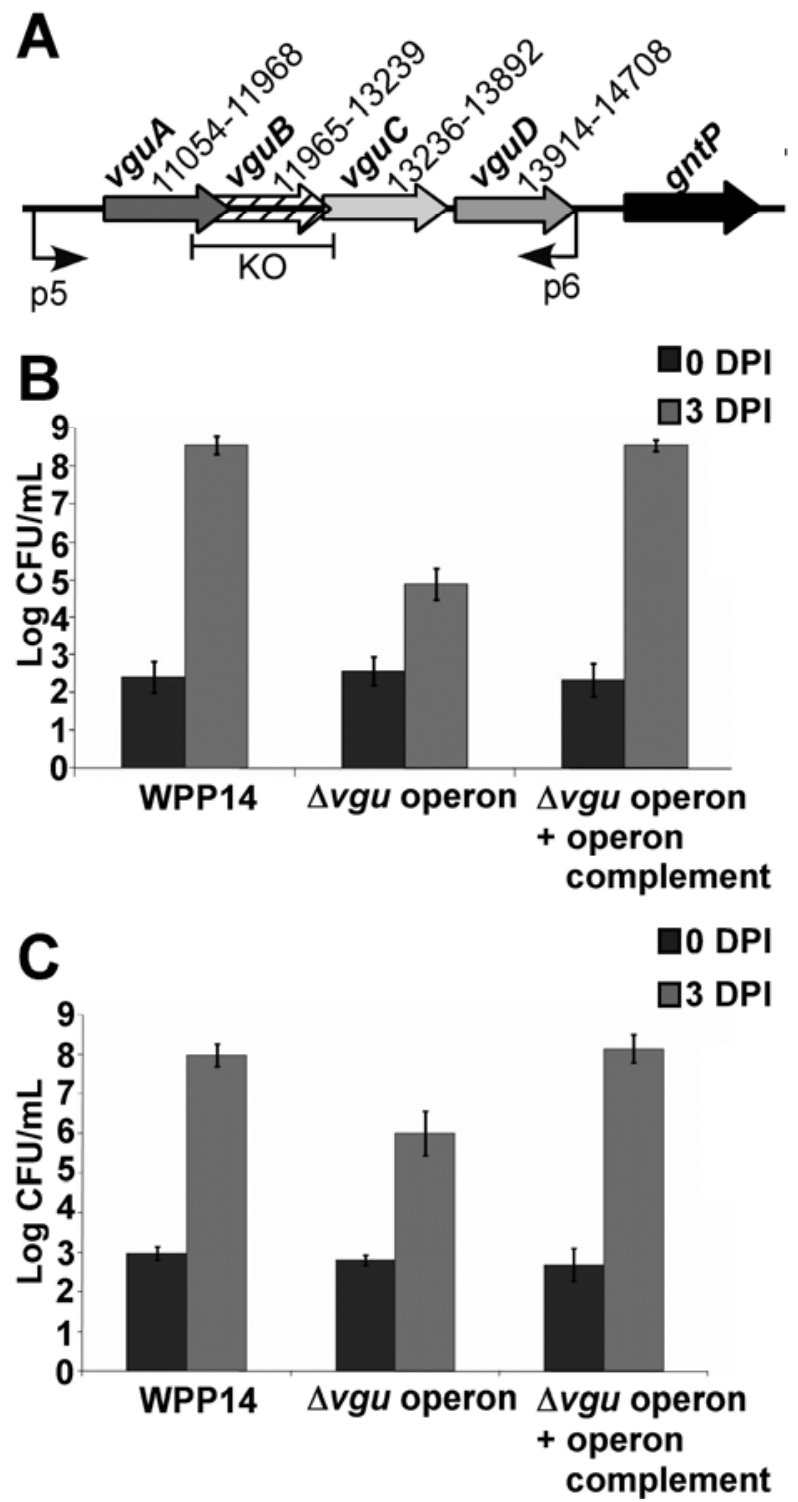

Fig. 1. The $v g u A B C D$ mutant was defective in growth on leaves. A, Schematic of the $v g u$ operon and mutant. Arrows represent open reading frames and their orientations; annotation IDs represent DNA coordinates in GenBank accession ABVY01000079. The region that was deleted, via homologous recombination, is represented by the $\mathrm{KO}$ bar. P5 and P6 refer to primers 5 and 6 which were used to construct the complementation clone. P5 is situated 500 bp upstream of the start codon of vguA. B, Potato and $\mathbf{C}$, Arabidopsis thaliana hand infiltration assays of Pectobacterium carotovorum subsp. carotovorum WPP14, the $v g u$ operon mutant, and the $v g u$ operon mutant carrying pCR2.1:vgu operon. Plants were inoculated with $10^{4} \mathrm{CFU} / \mathrm{ml}$ into leaves of 4- to 5-week-old plants. Y axis shows CFU/ml of extraction of buffer, in which a square centimeter of leaf tissue is ground on the day of inoculation (0 DPI) and 3 days later (3 DPI). The experiment has four internal replicates and was repeated three times; a representative experiment is shown, and error bars indicate two times standard error. al. 2000). FlhDC and HexA are responsive to unknown extracellular environmental factors, and HexA, in turn, regulates $r s m B$ expression. The sensor kinase GacS is thought to detect cell density, growth phase, and other undetermined environmental factors, while its cognate response regulator, GacA, is itself regulated by medium composition and growth phase (Kitten et al. 1998; de Souza et al. 2003; Cui et al. 2008). GacA regulates toxins, PCWDE, and $r \operatorname{smB}$ downstream of GacS (Chatterjee et al. 2003). In addition to regulating HexA and $\mathrm{GacA} / \mathrm{S}$, FlhDC in Escherichia coli is responsible for regulating a shift to aerobic respiration and genes involved in the Entner-Doudoroff pathway, an alternative glycolysis pathway (Pruss et al. 2003; Leatham et al. 2005). Thus, the activity of FlhDC not only provides a clear regulatory link between virulence and motility (Pruss et al. 2006) but between metabolism and environmental conditions as well.

We characterize a $P$. carotovorum operon required for gluconate metabolism that modulates the expression of key virulence regulators and affects virulence in plants. Boch and associates (2002) employed an in vivo expression technology screen in $P$. syringae for T3SS virulence determinants and identified a gene they designated ipx53. Gene ipx53 was considered a potential type III effector for a short time and assigned the name HopAN1. Unlike other T3SS effectors, this gene is highly conserved across enterobacteria and other bacterial plant pathogens (Miriagou et al. 2005; Grant et al. 2006; Zienkiewicz et al. 2007). The hopAN1 homolog of strain WPP14 exists in an operon of four genes encoding, in order: an oxidoreductase, hopAN1, a class II aldolase, and an isomerase (Glasner et al. 2008). The operon is highly conserved in enterobacteria and the four genes were named $y g b J K L$ and $M$ in E. coli, which are temporary names for genes of unknown function (Rudd 1998). Here, we find that the operon is required for gluconate and virulence and, thus, name the $P$. carotovorum operon $v g u A B C D$ for virulence and gluconate.

\section{RESULTS}

The vguABCD operon is widely distributed in proteobacteria.

The structure of the $v g u A B C D$ operon in $P$. carotovorum (Fig. 1A) is generally conserved in enterobacteria. A similar operon also exists in more distantly related plant-pathogenic bacteria, although one or two of the open reading frames (ORF) are missing in some species. The conservation of the operon structure in select proteobacteria is illustrated in Supplementary Figure S1, which shows a Bayesian inference of phylogeny tree (Huelsenbeck and Ronquist 2001). The operon is conserved in non-enterobacteria plant pathogens such as Ralstonia picketti and Pseudomonas syringae B728a. In many species, the chromosome regions are flanked by other genes predicted to be involved in sugar metabolism, such as epimerases and decarboxylases. The conserved genomic structure of this operon suggests that its products could be involved in a metabolic function.

The vgu operon mutant has significantly attenuated growth on potato and Arabidopsis leaves.

We constructed a deletion-insertion mutation that replaces $v g u B$ with a chloramphenicol cassette. This has a polar effect and disrupts the expression of both the up- and downstream overlapping genes in the operon as determined by reverse-transcription polymerase chain reaction (RT-PCR). This mutation does not affect expression of the next gene downstream, gntP, which encodes gluconate permease (data not shown). The mutation was confirmed by PCR and resequencing of the entire vgu operon. The $v g u$ operon mutant had the same growth rate as the 
wild type in $2 \times$ yeast extract tryptone (YT), tuber-extract, hrprepressing, and swimming minimal media (Supplementary Fig. S2), and was as tolerant to oxidative stress as the wild type using a hydrogen peroxide tolerance assay (data not shown). To determine whether the $v g u$ operon is involved in virulence, we compared growth of the wild type to that of the vgu operon mutant in its native host, potato (Fig. 1B), as well as a model host, Arabidopsis thaliana (Fig. 1C). In both potato and A. thaliana leaves, P. carotovorum subsp. carotovorum WPP14 grew to $10^{8} \mathrm{CFU} / \mathrm{ml}$ by 3 days postinfection. In potato leaves, the $v g u$ operon mutant grew three logs less than strain WPP14 by 3 days postinfection, illustrating a severe attenuation in virulence. Similarly, in $A$. thaliana leaves, the $v g u$ operon mutant grew two logs less than WPP14 by 3 days postinfiltration on leaves of both hosts. The $v g u$ operon mutant failed to produce maceration symptoms typically seen during Pectobacterium carotovorum infection on leaves of both hosts. These begin as a rotting lesion spreading from the site of infiltration over time. Both attenuation of growth and lack of maceration mutant phenotypes were rescued with the $v g u$ operon cloned with its native promoter in the entry clone pCR2.1 and mated into the $v g u$ operon mutant strain (Fig. 1).

\section{The vgu operon mutant hypermacerates potato tubers compared with the wild type.}

To determine whether the vgu operon mutant was also defective in tuber maceration, we compared wild-type maceration to that of the $v g u$ operon mutant. Each tuber was infected with three strains: P. carotovorum subsp. carotovorum WPP14, the $v g u$ operon mutant, and the complemented vgu operon mutant, as well as a negative control for maceration, $10 \mathrm{mM} \mathrm{MgCl}_{2}$ buffer. The wild type and the $v g u$ operon mutant carrying the complementation clone both macerated just over $1 \mathrm{~g}$ of potato tuber in 5 days, while the $v g u$ operon mutant macerated over $3 \mathrm{~g}$ of potato tuber (Fig. 2). The concentration of bacteria was approximately $1 \times 10^{9} \mathrm{CFU}$ per $100 \mathrm{mg}$ of macerated tuber tissue for both the mutant and the wild type. This indicated that the $v g u$ operon mutant is hypermacerating, suggesting a misregulation of the expression of PCWDE that characterize soft rotting diseases. This hypervirulence in the tuber was unexpected, given the attenuated virulence phenotypes on leaves reported above.

The vgu operon mutant is deficient in swimming motility.

Previous studies of $P$. carotovorum and other phytopathogens have demonstrated coregulation of motility modes during pathogenesis. Therefore, we compared the $v g u$ operon mutant

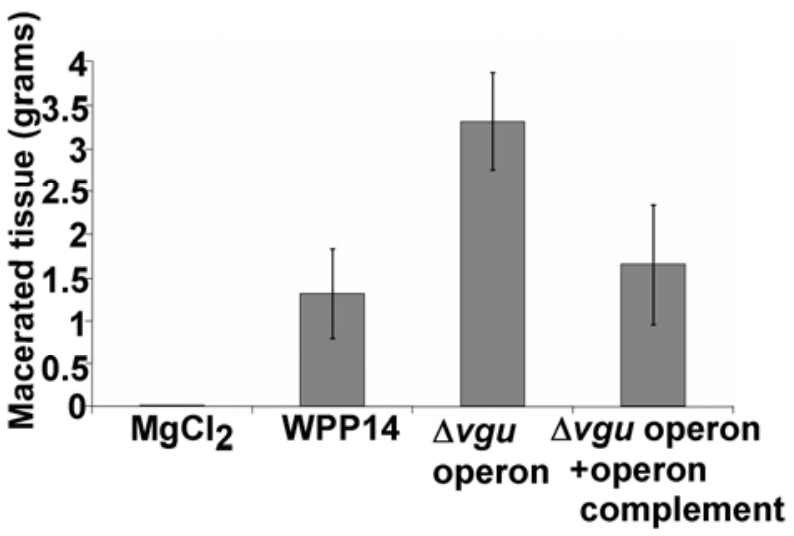

Fig. 2. The $v g u$ operon mutant hypermacerated infected potato tubers. Potato tubers were inoculated with either $10 \mathrm{mM} \mathrm{MgCl} 2$, Pectobacterium carotovorum subsp. carotovorum WPP14, the vgu operon mutant, or this mutant carrying pCR2.1:vgu operon. In all, $10^{6} \mathrm{CFU}$ were injected into a $1.5-\mathrm{mm}$ deep hole and tubers were incubated at $28^{\circ} \mathrm{C}$ for 5 days. The experiment had 10 internal replicates and was repeated twice; a representative experiment is shown, and error bars are two times standard error. with the wild type on twitching, swarming, and swimming motility agar plates. The $v g u$ operon mutant was able to swarm and twitch like wild-type strain WPP14; however, the $v g u$ operon mutant exhibited significant reduction in swimming plates. On swimming plates, the wild type and the vgu mutant carrying the complementation clone swam almost twice the diameter of the $v g u$ operon mutant (Fig. 3). This indicates that the $v g u$ operon mutant is also unable to properly swim or perform chemotaxis.

\section{The vgu operon is neither HrpL-regulated nor upregulated in leaves.}

$v g u B$ has homology to the Pseudomonas syringae gene originally annotated as a type III effector called hopAN1 (Lindeberg et al. 2005). We determined whether HrpL, the alternative sigma factor responsible for T3SS regulation in Pectobacterium carotovorum (Chatterjee et al. 2002), regulates vguB transcription in strain WPP14. Cultures of WPP14 containing the native hrpL ORF cloned under the control of an arabinose-inducible promoter in pCF430 (Chang et al. 2005) were grown with or without $200 \mathrm{mM}$ arabinose in $h r p L$-repressing media. Quantitative (q)RT-PCR was used to assess the relative expression of $v g u$ and a known HrpL-dependent T3SS effector, $d s p E$ (Fig. 4A). In the presence of overexpressed $h r p L$, expression of the type III effector gene $d s p E$ increased over 200-fold. However, $v g u$ expression was not significantly altered by $h r p L$ overexpression. By contrast to the Pseudomonas syringae hopAN1 gene, $v g u$ expression is also not induced in infected plants. We infiltrated $A$. thaliana leaves with wild-type strain WPP14 cultures with approximately $4 \times 10^{8} \mathrm{CFU} / \mathrm{ml}$. RNA was extracted $2.5 \mathrm{~h}$ postinfection. Simultaneously, a WPP14 culture was grown in $h r p$-repressing minimal media to the same concentration as the infiltrated culture, and RNA was extracted. qRTPCR performed using RNA from infected leaves or culture indicated that $h r p L$ transcription increased approximately sevenfold in leaves compared with expression in the hrp-repressing minimal media (Fig. 4B). The expression of $v g u B$, however, was not altered in leaves compared with minimal media and exhibited low-level expression in both conditions.

\section{The vgu operon mutant exhibits altered expression} of key virulence regulators in leaf infections and in the presence of tuber extract.

Our data indicated that virulence of the vgu operon mutant was attenuated in the leaf but overactive in the tuber. We used qRT-PCR to assess the expression level of known virulence

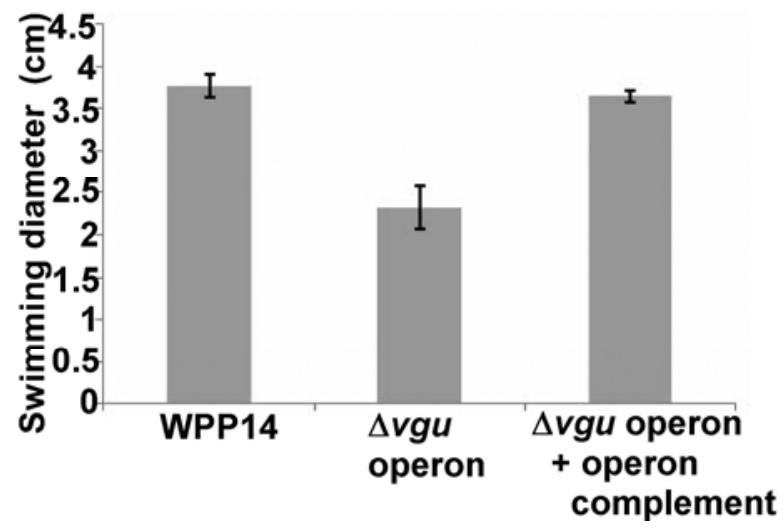

Fig. 3. The $v g u$ operon mutant was defective in swimming motility. Swimming motility plates were inoculated with $10^{6} \mathrm{CFU}$ into the center of the plate, each with $50 \mathrm{ml}$ of motility agar and appropriate antibiotics. Plates were grown for $18 \mathrm{~h}$ at room temperature. The experiment had four internal replicates and was repeated three times; a representative experiment is shown, and error bars are two times standard error. 
regulators in both conditions. In leaves, the $v g u$ operon mutant exhibited higher mRNA levels of $k d g R$ and the T3SS helper protein $h r p N$ than the wild type (Fig. 5A). In the presence of tuber extract, $f l h D$ (Cui et al. 2008) and the LysR-like transcription regulator, hexA (Harris et al. 1998), were severely downregulated in the $v g u$ mutant compared with the wild type (Fig. 5B). Though weakly expressed relative to the $f f h$ housekeeping gene control, $r s m B$ was also downregulated eightfold in the $v g u$ operon mutant compared with the complementation strain in the presence of tuber extract (Fig. 5B). Following leaf infection, $f l h D$ and $r s m B$ were expressed at very low levels in both the $v g u$ operon mutant and the wild type (Fig. 5A).

The vgu operon is required for gluconate metabolism.

To address whether the $v g u$ operon is involved in sugar metabolism, as BLAST analysis suggests, we used a phenoarray plate to assess the metabolic phenotype of our $v g u$ mutant in relation to the wild type. Wild-type strain WPP14 was capable

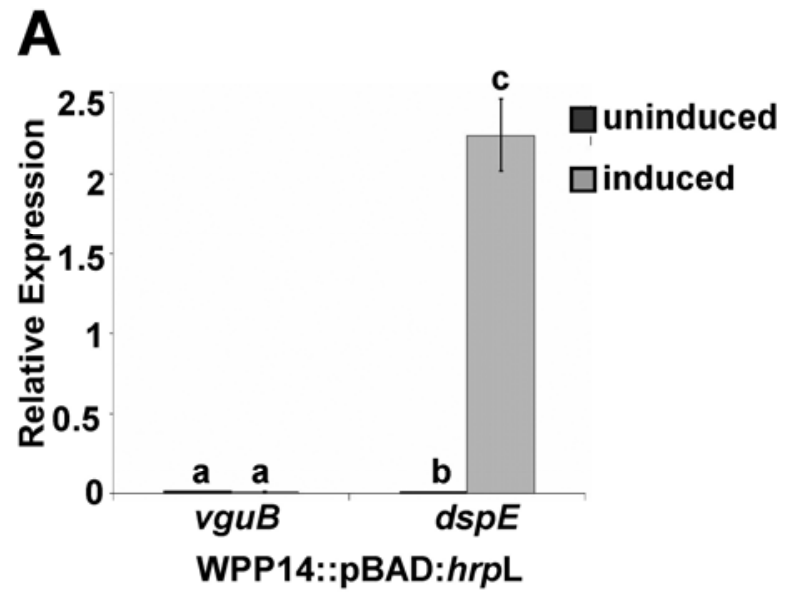

B

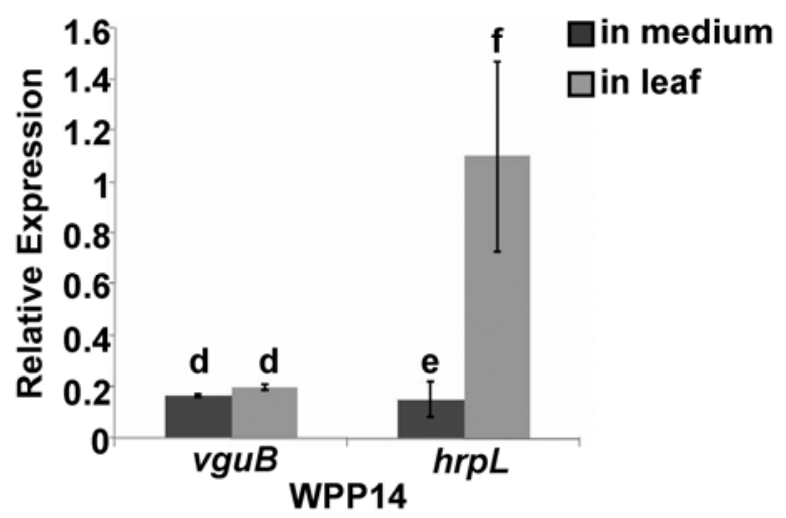

Fig. 4. Expression of the $v g u$ operon is independent of type III secretion system regulation. A, Quantitative reverse-transcription polymerase chain reaction (qRT-PCR) data showing relative expression of $v g u$ and $d s p E$ expressed in Pectobacterium carotovorum subsp. carotovorum WPP14 carrying pCF430 with $\mathrm{hrpL}_{\mathrm{WPP} 14}$. Cultures were grown in hrp-repressing minimal media and $h r p L$ expression was induced with $200 \mathrm{mM}$ arabinose. B, qRT-PCR data showing relative expression of $v g u$ and $h r p L$ expressed in WPP14. Strains were grown either in hrp-repressing minimal media overnight or infiltrated into Arabidopsis thaliana leaves at $10^{8} \mathrm{CFU} / \mathrm{ml}$ with RNA extraction $2.5 \mathrm{~h}$ postinoculation. Expression is relative to the $f f h$ housekeeping gene. Each experiment was repeated at least twice and includes three technical replicates; error bars are two times standard error. Lowercase letters represent significantly different groups determined using an analysis of variance and a Tukey test. $P$ values for expression differences between growth conditions are as follows: $\mathrm{A}, v g u B, P=0.2211$ and dspE, $P=1.552 \mathrm{e}^{-9} ; \mathrm{B}, v g u B, P=0.386$ and $h r p L, P=7.207 \mathrm{e}^{-5}$. of using all carbon sources tested, with the exception of D-gluconate (carbon sources tested are listed in Supplementary Table S2). The ability to grow on gluconate was rescued by the expression of the operon in the complementation strain. In Pectobacterium carotovorum, gluconate is a precursor sugar for the pentose phosphate pathway (Truesdell et al. 1991) and the first enzyme in the $v g u$ operon has similarity to the first enzyme in the pentose phosphate pathway, 6-phosphogluconate dehydrogenase. However, the mutant was able to grow as well as the wild type on carbon sources that are sugar intermediates of the pentose phosphate pathway, xylulose and ribulose. This indicates that these pentose sugars can be metabolized through multiple pathways or that the defect in the vgu mutant may be limited to early steps in the pentose phosphate pathway.

\section{The vgu operon is required}

for the accumulation of pentose sugars.

We compared the metabolite profiles of wild-type $P$. carotovorum subsp. carotovorum WPP14 and the vgu mutant grown in tuber extract media by gas chromatography (GC) coupled to mass spectrometry (MS). Cultures were grown in tuber extract media and metabolites were extracted during a cold chloroform extraction protocol established for GC-MS metabolite profiling by Ruijter and Visser (1996). We found six differential peaks in the chromatograph of the wild type and the vgu operon mutant (Table 1). One of the peaks was present in the
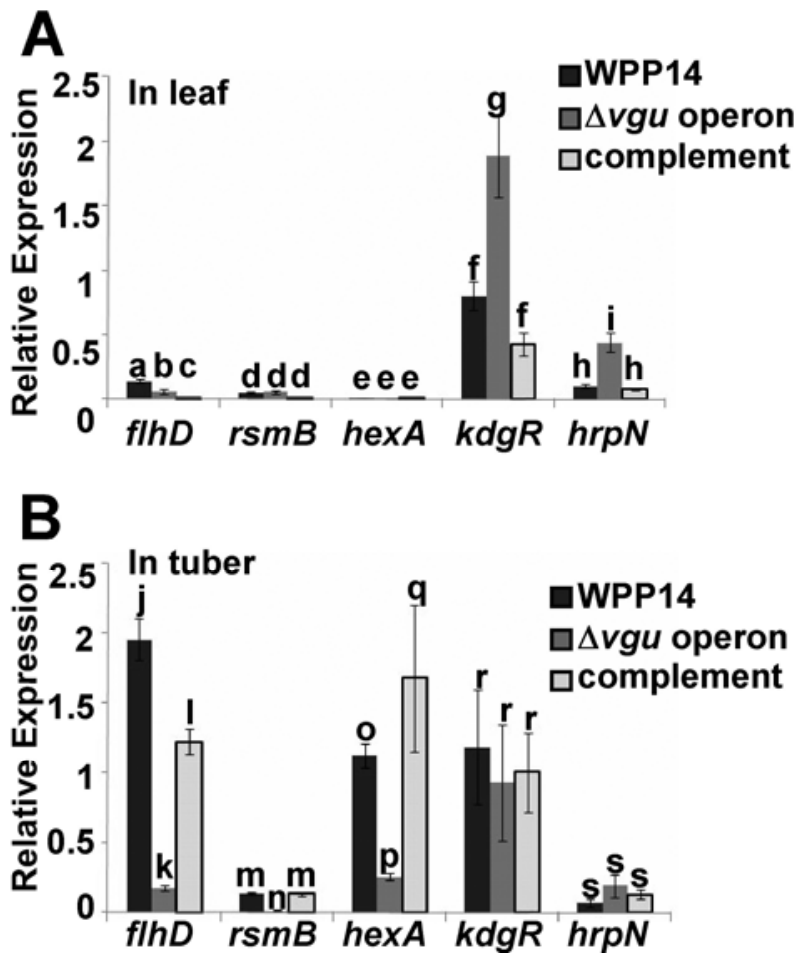

Fig. 5. The $v g u$ operon is required for normal expression of key virulence regulators in leaf and tuber extract. Quantitative reverse-transcription polymerase chain reaction data illustrates relative expression of key virulence regulators and determinants in Pectobacterium carotovorum subsp. carotovorum WPP14, the $v g u$ operon mutant, or the $v g u$ operon mutant carrying pCR2.1:vgu operon, from leaf infection conditions after $2.5 \mathrm{~h}$ and in the presence of tuber extract after $3 \mathrm{~h}$ of growth. Expression is relative to the ffh housekeeping gene. Each experiment was repeated at least twice and includes three technical replicates; error bars are two times standard error. Lowercase letters represent significantly different groups determined using an analysis of variance and a Tukey test. $P$ values are as follows, for genotype-dependent differences in expression in the leaf: flhD, $P=0.0264 ; r s m B$, $P=3.75 \mathrm{e}^{-7}$; hexA, $P=0.7054 ; k d g R, P=0.00205 ;$ hrpN,$P=0.0005$; and in the tuber: flhD $P=3.226 \mathrm{e}^{-5} ; \operatorname{rsmB}, P=0.000634$; hexA, $P=3.735 \mathrm{e}^{-7}$; $k d g R, P=0.1180 ;$ hrpN, $P=0.0769$. 
mutant but absent in the wild type. The mass spectrograph of that peak matched that of chloramphenicol, the antibiotic selection that is used for the mutant, but not the wild type, and the only known difference in the media composition between the two strains. The remaining five chromatograph peaks were all present in the wild type but absent in the mutant. One peak had a mass spectrograph that resembled that of 2-phenyl-2,3dihydrobenxothiophene. It is unclear how this derivatized metabolite relates to the $v g u$ operon mutant's metabolic deficiency. The remaining four spectrographs represent silylated sugar derivatives, including D-gluconic acid, ribose, erythropentose, and sedoheptulose. Erythropentose, ribose, and sedoheptulose are intermediates involved in the pentose-phosphate shunt. D-gluconic acid is the precursor sugar for this pathway, suggesting that upstream catabolism is also altered in the vgu operon mutant. It should be noted that the $P$. carotovorum genome encodes two gluconate transporters, one of which is encoded just downstream of the $v g u$ operon. Because the $v g u$ mutation does not alter expression of the downstream transporter (data not shown), we anticipate that the reduced gluconate levels are due to the lack of the $v g u$ operon-encoded functions. As a control, pure forms of these sugars (Sigma-Aldrich, St. Louis) were derivatized and analyzed with GC-MS to confirm the identity of the metabolite ion profiles that differed between the mutant and the wild type.

\section{DISCUSSION}

We demonstrate that the $v g u$ operon is involved in gluconate metabolism and is required for proper expression of virulence via $\mathrm{KdgR}$, FlhD, HexA, and the rsm system. A mutant lacking the $v g u$ operon has attenuated virulence in leaves, hypermacerates potato tubers, and is deficient in motility. The inability of the mutant to grow on gluconate and its lack of intermediate pentose sugars from gluconate metabolism suggests that the $v g u$ operon encodes enzymes for gluconate metabolism. In $P$. carotovorum, glucose can be oxidized to 2,5-diketogluconate, reduced to gluconate, and subsequently metabolized through the pentose phosphate pathway as it is in related species (Truesdell et al. 1991). The predicted functions of the $v g u$ operon-encoded proteins suggest that they operate in a pathway similar to the pentose phosphate pathway. Thus, we provide evidence suggesting that gluconate catabolism affects virulence determinants by modulating known regulators.

\section{Gluconate metabolism in $P$. carotovorum.}

In environments with high glucose concentrations, many bacteria oxidize glucose extracellularly to gluconate or 2-ketogluconate through membrane-bound dehydrogenases. When glucose is depleted in the environment, the oxidized glucose can be transported into the cell and phosphorylated in an ATPdependent manner, forming 6-phosphogluconate or 2-keto-6phosphogluconate, respectively. These phosphorylated, intra- cellular sugars can then be used for the Entner-Dourdoroff pathway, an alternative to the Embden-Meyerhof-Parnas glycolysis pathway, or the pentose phosphate shunt (Eisenberg and Dobrogosz 1967; Truesdell et al. 1991; Murray and Conway 2005).

The genome of $P$. carotovorum encodes genes for ketoaldonic acid metabolism and may oxidize extracellular glucose to 2,5diketogluconate, which can be reduced to gluconate in two separate pathways (Truesdell et al. 1991). However, once in the cell, 6-phosphogluconate may solely be metabolized through the pentose phosphate pathway, because enzymes for the ED pathway were not found in significant levels in a related species (Truesdell et al. 1991). Generally, if 6-phosphogluconate were to be metabolized through the pentose phosphate shunt, it would first be converted to ribulose 5-phosphate by the enzyme 6phosphogluconate dehydrogenase, which is then converted to ribose 5-phosphate. The first gene in the $v g u$ operon has high similarity to 6-phosphogluconate dehydrogenase. Consistent with this prediction, preliminary GC-MS data indicates that ribose does not accumulate in the $v g u$ operon mutant.

The ribose 5-phosphate resulting from the first step of the pathway is further rearranged by transaldolases and isomerases to 6-glucose-phosphate and glyceraldehyde 3-phosphate. Although $v g u B$, the second gene in the operon, does not have similarity to any other protein with a known function, the last two operon members encode a putative aldolase and isomerase. It should be noted that the $P$. catorovorum genome contains genes predicted to encode all other enzymes typically involved in the pentose phosphate pathway, However, these other enzymes are dispersed around the genome and many are neither within an operon nor clustered with other metabolic genes. Our observation that the $v g u$ operon mutant is incapable of metabolizing gluconate suggests that these other predicted enzymes either are not expressed in the conditions we tested or are involved in different pathways. Using GC-MS, we compared the metabolite profiles of the wild type and the operon mutant and found the mutant deficient in accumulation of pentose sugar intermediates of the pentose phosphate pathway. Therefore, based on our evidence that the $v g u$ operon is required for gluconate metabolism and the operon member's homology to enzymes in the pathway, we predict that the $v g u$ operon is involved in a pathway similar to the pentose phosphate pathway.

The pentose phosphate pathway is also a main method for generating reducing power via the production of NADPH, which can be used to prevent oxidative stress. Plant hosts produce reactive oxygen species as a defense against invasion (Dong 2004). However, in oxidative stress assays using hydrogen peroxide, the $v g u$ operon mutant was not more sensitive than the wild type to oxidative stress. Additionally, the vgu operon mutant did not produce different $\mathrm{pH}$ conditions in macerated tuber tissue or in medium, suggesting that the virulence phenotypes of the vgu operon mutant are not due to stress conditions in the host.

Table 1. Gas chromatography-mass spectrometry metabolic profiles show the vgu mutant to be depleted of sugars that are the immediate precursor and the products of the pentose phosphate pathway ${ }^{\mathrm{a}}$

\begin{tabular}{|c|c|c|c|c|}
\hline Metabolite & $\mathbf{W T}^{\mathbf{b}}$ & $v g u$ & Time $^{c}$ & Spectrograph peaks ${ }^{d}$ \\
\hline Gluconic acid & + & - & 16.91 & $73-387-299-315-357$ \\
\hline 2-Phenyl-2,3-dihydrobenzo[b]thiopene & + & - & 17.59 & $212-211-134-135-178$ \\
\hline Erythropentose & + & - & 18.6 & $73-315-357-299-217$ \\
\hline D-ribose & + & - & 20.15 & $73-315-217-299-316$ \\
\hline $\mathrm{O}, \mathrm{O}$ bis chloramphenicol & - & + & 20.2 & $73-225-208-75-224$ \\
\hline Sedoheptulose & + & - & 20.53 & 204-73-191-217-205 \\
\hline
\end{tabular}

${ }^{\text {a }}$ Differential presence (+) or absence (-) of metabolite.

${ }^{\mathrm{b}}$ Wild type.

c Time metabolite peak was detected in the chromatograph.

d Top five signature peaks of the mass spectrogram for that metabolite peak. 
Gluconate metabolism affects the expression of key regulators.

Previous studies identified a complex network of transcriptional and post-transcriptional virulence regulators (Barnard and Salmond 2007; Barnard et al. 2007; Mole et al. 2007) that regulate virulence determinants such as the T2SS and macerating enzymes, the T3SS, motility, quorum sensing, and antibiotic production. We evaluated the expression of these known key regulators in the $v g u$ mutant to better understand the virulence phenotypes.

In leaves, the $v g u$ operon mutant overexpresses $k d g R$, a transcriptional repressor known to regulate $h r p N$ and genes encoding macerating enzymes (Liu et al. 1999). KdgR activity is responsive to pectin breakdown products and $\mathrm{KdgR}$ releases from target promoters after binding to catabolic intermediates of pectin degradation (Pouyssegur and Stoeber 1974; Nasser et al. 1991; Liu et al. 1999). Therefore, in the presence of pectin and its catabolic intermediates, such as polygalacturonate (PGA), the $\mathrm{KdgR}$ repressor activity is blocked and $\mathrm{KdgR}$ targets, such as genes encoding macerating enzymes and $h r p N$, are expressed.

Gluconate and, presumably, the catabolic intermediates of gluconate inhibit the production of macerating enzymes in the presence of KdgR inducers PGA and galacturonate (Nasser et al. 1991). Accordingly, in our $v g u$ operon mutant, we observed hypermaceration in tubers and an increase in $h r p N$ expression. The absence of gluconate metabolism in this mutant may allow for macerating enzymes and $h r p N$ to be expressed unabated. $\mathrm{HrpN}$ is a T3SS-associatd helper protein, known to induce plant defense responses. Overexpression of $h r p N$ in $P$. carotovorum has been shown to induce a defense response of infected tobacco leaves (Cui et al. 1996), and purified HrpN protein from $P$. carotovorum can induce hypersensitive responses indicative of induced host defenses when applied to A. thaliana leaves (Kariola et al. 2003). Therefore, the induced defense responses caused by elevated expression of $h r p N$ in the $v g u$ operon mu-

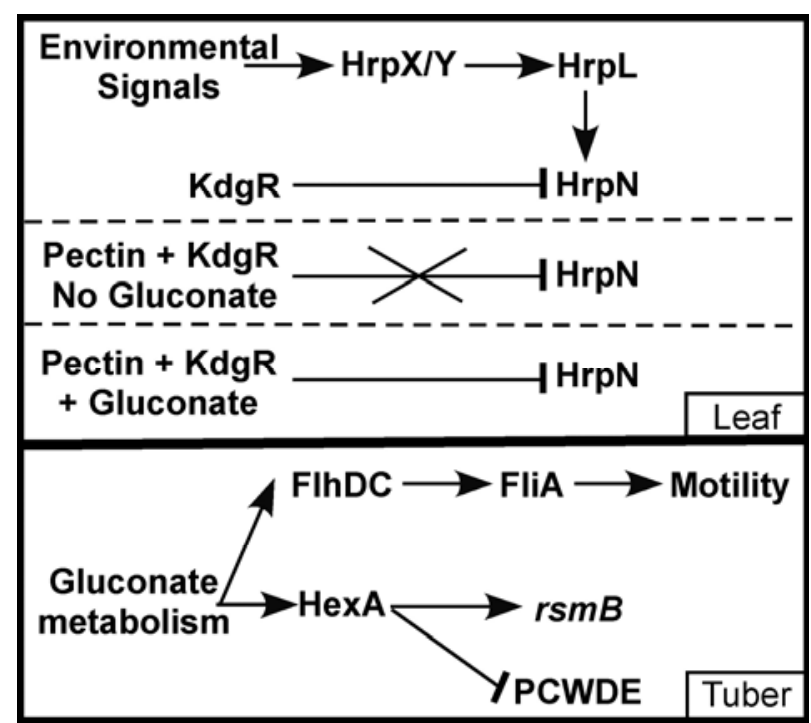

Fig. 6. Hypothetical model of the $v g u$ operon's role in virulence. KdgR blocks transcription of macerating enzymes and $h r p N$ in the absence of pectin breakdown products. In the presence of only pectin, KdgR repressor activity is blocked and its target genes, such as $h r p N$, can be expressed. In the vgu mutant, which does not metabolize gluconate, we see overexpression of the KdgR target gene, $h r p N$. In the presence of gluconate, $\mathrm{KdgR}$ is not blocked by the presence of pectin and KdgR target genes are not expressed. $h r p N$ is also under the control of $\mathrm{HrpL}$, which is responsive to the two-component signal transduction system, HrpX/Y. Gluconate metabolism also regulates FlhDC and HexA through unknown mechanisms. FlhDC is known to regulate motility and HexA regulates $r s m B$ and plant cell-wall-degrading enzymes. tant may be sufficient to explain its loss of virulence on leaves. A model for this is shown in Figure 6A, in which KdgR repressor activity is blocked by pectin breakdown products but sustained with the addition of gluconate. From our data and the previously published data by Nasser and associates (1991), we hypothesize that the catabolic pathways for pectin and gluconate are antagonistic. The increase that we see in $k d g R$ expression in the $v g u$ operon mutant is presumably due to autoregulation of the repressor; however, there is no data on the regulation of $k d g R$.

In tuber extract media, the $v g u$ operon mutant shows no relative changes in $k d g R$ or $h r p N$ expression. However, the $v g u$ operon mutant does exhibit downregulation of $f l h D$, hexA, and rsmB in tuber extract compared with the wild type. These genes are weakly expressed in both the wild type and the mutant during leaf infection. The FlhDC complex was first identified as the master regulator of motility (Smith and Hoover 2009) in $E$. coli, and regulates the switch from aerobic respiration to anaerobic respiration (Pruss et al. 2003). FlhDC interacts with HexA, a LysR-like transcription factor, as well as with the Rsm system (Chatterjee et al. 2009). HexA directly binds the promoters of genes encoding extracellular enzymes. The loss of HexA was previously reported to cause a hypermacerating phenotype (Harris et al. 1998). This explains how our $v g u$ operon mutant, which has relatively weak expression of hexA, hypermacerates the tuber. Likewise, downregulation of $f l h D$, the master regulator of the flagellar system, in the $v g u$ operon mutant can explain the deficiency in motility that we observed on motility plates. Previous studies, however, have indicated that FlhD and HexA activity are antagonistic (Chatterjee et al. 2009). This begs an explanation for how both could be downregulated simultaneously in our $v g u$ operon mutant. The answer may lie in unresolved environmental factors that can putatively influence the expression of both $f l h D$ and hexA. For example, $f l h D$ is regulated by FliT, which is responsive to unknown environmental factors (Chatterjee et al. 2009). Similarly, hexA expression is also mediated by unknown environmental factors through an unknown mechanism (Chatterjee et al. 2009). We propose a model (Fig. 6B) for the influence of the $v g u$ operon and inferred gluconate catabolic intermediates on these key regulators during tuber infection that correlates the observed phenotypes, expression data, and published regulatory network information (Barnard et al. 2007; Cui et al. 2008).

Although it is surprising that the vgu operon mutant is attenuated for virulence in the leaf while being hypervirulent in the tuber, the two in planta environments are very different. The tuber environment is anaerobic and contains a high level of starch. Thus, it is a glucose-rich environment. The apoplastic spaces of the leaf are aerobic and nutrient-poor (Rico and Preston 2008). Nutrient availability and other environmental factors have dramatic effects on virulence. For instance, $h r p N$ is regulated by the alternative sigma factor $\mathrm{HrpL}$ in addition to $\mathrm{KdgR}$. HrpL is activated by a two-component system, $\mathrm{HrpX} / \mathrm{Y}$, that is responsive to unknown exogenous metabolites. In tubers, HrpL is not upregulated by $\mathrm{HrpX} / \mathrm{Y}$ and, thus, does not activate $h r p N$ in either the wild-type WPP14 or the vgu operon mutant.

\section{Conclusion and outlook.}

The life history of $P$. carotovorum, encompassing saprophytic environmental microbe to opportunistic phytopathogen, demands the ability to sense environmental shifts and to respond accordingly. Despite existing data on the network of regulators that control expression of virulence in $P$. carotovorum, it is still unclear what environmental signals are monitored to determine virulence expression. Here, we identified an operon that encodes enzymes necessary for gluconate metabolism that acts as a cue for virulence regulation. Our model for how the actions of 
these enzymes affect the expression of virulence regulators favors the straightforward hypothesis that catabolic intermediates are, themselves, cues. However, competing hypotheses include more interplay or antagonism between metabolic pathways and differences in metabolic fluxes that can influence virulence expression. There is evidence to support these hypotheses, including the role of FlhDC in E. coli in the switch from aerobic to anaerobic respiration (Pruss et al. 2003; Leatham et al. 2005) and the role of gluconate to interfere with $\mathrm{KDG}$ binding to $\mathrm{KdgR}$. However, more work is needed to elucidate the role of nutrient availability and subsequent metabolic network fluxes on virulence expression and the mechanisms by which these cues act.

\section{MATERIALS AND METHODS}

Bacterial strains, plasmids, and media.

Bacterial strains were maintained in lysogeny broth (LB) agar or $2 \times$ YT broth, containing appropriate antibiotics (Sambrook and Russell 2001). The minimal media for $h r p L$ repression was described by Chang and associates (2005). Tuber extract media was made by autoclaving $200 \mathrm{~g}$ of chopped Yukon gold potatoes with $200 \mathrm{ml}$ of water. After autoclaving, the waterpotato slurry was centrifuged at $12,000 \times g$ for $30 \mathrm{~min}$. The supernatant was diluted 1:5 in M9 minimal media lacking a carbon source. When required, antibiotics and drugs were supplemented at the following concentrations: ampicillin (Amp), $100 \mu \mathrm{g} / \mathrm{ml}$; chloramphenicol $(\mathrm{Cm}), 30 \mu \mathrm{g} / \mathrm{ml}$; gentamicin, 25 $\mu \mathrm{g} / \mathrm{ml}$; kanamycin (Kan), $30 \mu \mathrm{g} / \mathrm{ml}$; rifampicin, $100 \mu \mathrm{g} / \mathrm{ml}$; spectinomycin, $50 \mu \mathrm{g} / \mathrm{ml}$; and tetracycline, $5 \mu \mathrm{g} / \mathrm{ml}$. Media was solidified with $1.5 \%$ (wt/vol) Bacto agar (BD Biosciences, San Jose, CA, U.S.A.). Cultures were grown at $28^{\circ} \mathrm{C}$ and, if in liquid, shaken at $250 \mathrm{rpm}$.

\section{DNA manipulations.}

Standard procedures were used for plasmid and chromosomal DNA isolation, electroporation, restriction endonuclease digestions, ligations, gel electrophoresis, and triparental mating. Enzymes were obtained from either New England Biolabs (Beverly, MA, U.S.A.) or Invitrogen (Carlsbad, CA, U.S.A.). Nucleotide sequences were determined by the University of North Carolina-Chapel Hill Genome Analysis Facility and sequences were analyzed using BLAST (Altschul et al. 1990).

\section{Construction of the $P$. carotovorum vgu operon mutant.}

To replace the $v g u$ operon, we used splicing overlap extension (SOE) PCR (Horton et al. 1989) to create a construct with a $\mathrm{Cm}$ cassette flanked by $1 \mathrm{~kb}$ of sequence surrounding $v g u B$ on each side. The $v g u B$ reading frame overlaps the downstream and upstream genes, $v g u A$ and $v g u C$, respectively, by $4 \mathrm{bp}$ each (Fig. 1). Briefly, a 1-kb region upstream of $v g u B$ was amplified using SOE primers containing a SalI site for the insertion of a $\mathrm{Cm}$ cassette on the $3^{\prime}$ end, and a 1-kb downstream region was amplified similarly with the SalI site on the $5^{\prime}$ end with SOE primers (Supplementary Table S1, primers 1 and 2). These amplicons were then fused together in a two-step SOE PCR reaction and the SOE product was cloned into pCR2.1 Topo TA cloning vector $\left(\mathrm{Amp}^{\mathrm{r}}\right)$ (Invitrogen) to make pCR2.1SOEvgu, which was then digested with SalI. The $\mathrm{Cm}$ cassette was amplified from pKD3 using modified primers from Datsenko and Wanner (2000) to contain SalI sites on both ends. The $\mathrm{Cm}$ cassette was then digested with SalI and ligated to the linear pCR2.1SOEvgu to make pCR2.1svgu. This plasmid was introduced into $P$. carotovorum WPP14 by electroporation. The resulting WPP14::pCR2.1 $\Delta v g u$ strain was then grown in potassium phosphate buffer supplemented with $\mathrm{Cm}$ but not Amp. After overnight growth, the cultures were transferred to $2 \times$ YT supplemented with $\mathrm{Cm}$ and passaged for 3 days, at which point the cultures were replica plated on LB plates that contained either $\mathrm{Cm}$ and Amp or just $\mathrm{Cm}$, to identify strains that had lost the plasmid but undergone doublehomologous recombination for marker exchange. The resulting deletion-insertion mutants were verified by PCR analysis and sequencing across the entire four-gene operon.

\section{Complementation of $v g u$ operon mutant.}

The four-gene operon and a 500-bp region encompassing the operon promoter region were amplified with $p f x$ polymerase (Invitrogen) with primers 5 and 6. Gel electrophoresis with a $1 \%$ (wt/vol) agarose (Invitrogen ultrapure agarose) was used to view and isolate the resulting amplicon. Gel extraction buffers and protocols were supplied from Qiagen Gel extraction kit (Qiagen, Basel, Switzerland). The isolated amplicon was then incubated in the presence of Taq polymerase (Invitrogen) and a PCR reaction mix without primers for $5 \mathrm{~min}$ at $70^{\circ} \mathrm{C}$ in order to add overhanging As on the blunt amplicon. The amplicon was then cloned into pCR2.1 TA cloning vector (Invitrogen TA cloning kit) according to the manufacturer's protocol. The resulting plasmid was then conjugated into the $P$. carotovorum $v g u$ operon mutant via triparental mating with $E$. coli helper strain pRK2013. The resulting complementation strain was isolated on $\mathrm{Cm}$ and Kan plates and verified by PCR from vector-borne M13 primers (Invitrogen).

\section{A. thaliana and potato leaf infection assay.}

Cultures were grown overnight in $2 \times$ YT media, washed twice in $10 \mathrm{mM} \mathrm{MgCl}$, and resuspended at $10^{4} \mathrm{CFU} / \mathrm{ml}$ in 10 $\mathrm{mM} \mathrm{MgCl}$. Cultures were hand infiltrated with a needle-less 1-ml syringe into the leaves of either 4- to 5-week-old Yukon gold potatoes or 4- to 5-week-old A. thaliana. At subsequent time points, infected leaves were cored with a 6-mm-diameter cork borer and the tissue ground in the presence of $10 \mathrm{mM}$ $\mathrm{MgCl}_{2}$. The CFU per milliliter of present bacteria was quantified by titration and plating on LB plates with the appropriate antibiotics.

\section{Tuber maceration assay.}

Tubers were injected with $10 \mu \mathrm{l}$ of bacteria resuspended in $\mathrm{MgCl}_{2}$ at a concentration of $10^{8} \mathrm{CFU} / \mathrm{ml}$. Bacteria were inoculated into $15-\mathrm{mm}$ holes in the tuber, made with a pipette tip. The infected tubers were then placed in a plastic bag, which was sealed and kept at $28^{\circ} \mathrm{C}$ for 5 days. After 5 days, the soft, macerated tissue surrounding each injection site was carefully scooped out using a metal spatula and weighed. Each experiment contained 10 internal replicates.

\section{Motility assays.}

Motility media recipes were described by Rashid and Kornberg (2000). Swimming motility media contained tryptone (10 g/liter), $\mathrm{NaCl}$ (5 g/liter), and Bacto-Agar (BD) at $0.3 \% \mathrm{wt} / \mathrm{vol}$. Swarming motility media contained nutrient broth (8 g/liter) and Bacto-Agar at $0.5 \% \mathrm{wt} / \mathrm{vol}$. Twitching motility media contained tryptone (10 g/liter), yeast extract (5 g/liter), $\mathrm{NaCl}$ (10 g/liter), and Bacto-agar at 1\% wt/vol. Each motility plate contained $50 \mathrm{ml}$ of motility media with appropriate antibiotics. Plates were inoculated with $10^{6} \mathrm{CFU}$ of bacteria and incubated for $18 \mathrm{~h}$ at room temperature, at which point the diameter of the colony was measured.

\section{RNA extraction.}

From leaves. A. thaliana or potato leaves were infiltrated with wild-type WPP14 cultures at an optical density at $600 \mathrm{~nm}$ $\left(\mathrm{OD}_{600}\right)$ of 1.0 (approximately $4 \times 10^{8} \mathrm{CFU} / \mathrm{ml}$ ) using a needle-less syringe. At $2.5 \mathrm{~h}$ postinfection, 10 leaves were col- 
lected, ground in the presence of Qiagen Protect Bacteria, and homogenized over a Qiashredder column before RNA was extracted using the RNeasy kit (Qiagen).

From tuber extract media. Cultures were grown in rich media overnight, centrifuged, and washed in $10 \mathrm{mM} \mathrm{MgCl}_{2}$. Bacteria were resuspended at an $\mathrm{OD}_{600}$ of $0.5\left(2 \times 10^{8}\right.$ $\mathrm{CFU} / \mathrm{ml}$ ) and grown for $3 \mathrm{~h}$ with shaking at $28^{\circ} \mathrm{C}$. Bacteria were then harvested in the presence of Protect Bacteria (Qiagen) and RNA was extracted with the RNeasy mini kit (Qiagen) according to the manufacturer's protocol. However, the protocol was modified to include an RNA precipitation step with $\mathrm{LiCl}$ after lysis but before the ethanol precipitation and RNA being bound to the column. This step removed excessive sugars present in the tuber extract media.

\section{qRT-PCR.}

RNA was reverse transcribed into cDNA using the Ambion RETROscript kit. Briefly, $2 \mu \mathrm{g}$ of RNA was primed with random decamers and reverse transcribed with the MMLV-RT enzyme. cDNA was then diluted and relative quantities of specific transcripts were determined using SYBR Green RT-PCR reagents. Fluorescence of double-stranded DNA was measured by a DNA Engine, Opticon 2 continuous fluorescence detector (MJ Research, San Francisco) and values were analyzed using Opticon Monitor 3 software (MJ Research). Relative gene expression was determined by normalizing to a $P$. carotovorum housekeeping gene, $f f h$, which encodes a signal recognition particle protein, and was identified as an optimally stable control gene for qRT-PCR analysis by (Takle et al. 2007). Significance of differentially expressed genes was determined by an analysis of variance with a Tukey test using Jump v8 software (SAS Institute Inc., Cary, NC, U.S.A.).

\section{Hydrogen peroxide tolerance assay.}

Overnight cultures were centrifuged, washed with $200 \mathrm{mM}$ $\mathrm{MgCl}_{2}$, and resuspended at $2 \times 10^{8} \mathrm{CFU} / \mathrm{ml}$. Cultures were then incubated for $30 \mathrm{~min}$ in hydrogen peroxide at concentrations of $0.1,1,10$, or $100 \mathrm{mM}$. Each culture at a given concentration of hydrogen peroxide was done in triplicate. Cultures were then titrated and plated.

\section{Carbon source utilization assays.}

Biolog GN2 plates, which contain 95 discrete carbon sources, were inoculated with $P$. carotovorum WPP14, the vgu operon mutant, and the complemented vgu operon mutant. Briefly, cells were grown in $\mathrm{LB}$ media at $28^{\circ} \mathrm{C}$ for $24 \mathrm{~h}$, washed twice in $10 \mathrm{mM} \mathrm{MgCl}_{2}$, and resuspended in $10 \mathrm{mM}$ $\mathrm{MgCl}_{2}$ to a final concentration at $\mathrm{OD}_{600}$ of 0.4 . Aliquots of 150 $\mu \mathrm{l}$ were added to each well. The plates were sealed and allowed to incubate statically at room temperature for $24 \mathrm{~h}$. Each plate contained a negative control that lacked a carbon source to ensure that metabolic activity of stored carbon reserves was not being measured. In response to respiration, tetrazolium in each well was reduced to produce a distinctive purple color indicating the oxidization of the available carbon source. Carbon utilization was additionally tested by growth in M9 salts and $100 \mathrm{mM}$ of a specific carbon source. Bacteria were grown in liquid $2 \times$ YT culture overnight, washed in M9 salts two times, and resuspended at an $\mathrm{OD}_{600}$ of 0.04 in the M9 salts with a carbon source. The culture was then incubated for 18 to $20 \mathrm{~h}$ at $28^{\circ} \mathrm{C}$, while shaking, and the $\mathrm{OD}_{600}$ was measured again.

\section{GC-MS}

Preparation and methods for GC-MS analysis was as described (Koek et al. 2006). Cultures of the wild type and the $v g u$ operon mutant were grown from single colonies in LB me- dia overnight. The next day, overnight cultures were used to inoculate $100 \mathrm{ml}$ of potato extract media and grown to an $\mathrm{OD}_{600}$ of 0.4 in approximately $4 \mathrm{~h}$ with shaking at $250 \mathrm{rpm}$ at $28^{\circ} \mathrm{C}$. Cellular metabolism was immediately quenched by the addition of $160 \mathrm{ml}$ of methanol quenching buffer at $-45^{\circ} \mathrm{C}$ to $40 \mathrm{ml}$ of culture. Intracellular metabolites were extracted with chloroform as described by Ruijter and Visser (1996). At $-45^{\circ} \mathrm{C}$, chloroform was added to the methanol-water mixture to break the cell walls and denature enzymes. The water-methanol phase was then lyophilized and derivatized with $10 \mu \mathrm{l}$ of a 56 $\mathrm{mg} / \mathrm{ml}$ ethoxyamine hydrochloride solution in pyridine and 20 $\mu \mathrm{l}$ of pyridine. The samples were then incubated at $40^{\circ} \mathrm{C}$ for 90 min. The samples were then silylated for $50 \mathrm{~min}$ at $40^{\circ} \mathrm{C}$ with $70 \mu \mathrm{l}$ of $\mathrm{N}$-methyl- $N$-trimethylsilyltrifluoroacetamide. The derivatized extracts were prepared for GC-MS analysis by the addition of ethyl acetate as a carrier and filtering in the presence of acetyl nitrile to ensure the absence of metal ions. Samples were analyzed with an Agilent 6850 gas chromatograph coupled to an Agilent 5973 mass selective detector. The 5- $\mu$ l aliquots of extract were injected into a capillary column $(30 \mathrm{~m}$ $\times .25 \mathrm{~mm}$ i.d., $0.25-\mathrm{mm}$ film thickness) at $250^{\circ} \mathrm{C}$. The initial temperature of the gas chromatograph was $50^{\circ} \mathrm{C}$ and held for 3 min before ramping to $250^{\circ} \mathrm{C}$ at $10^{\circ} \mathrm{C} / \mathrm{min}$. Helium was used as a carrier gas. Detection was achieved using MS detection in electron impact mode and full scan monitoring mode $(\mathrm{m} / \mathrm{z} 10$ to 550). Data was analyzed using ChemStation (Enhanced Software, Mumbai, India).

\section{ACKNOWLEDGMENTS}

We thank A. Charkowski at the University of Wisconsin-Madison for providing the Pectobacterium carotovorum subsp. carotovorum WPP14 strain and for invaluable advice and encouragement; and A. Matthysse, R. Bourret, M. Wolfgang, M. Nishimura, and D. Baltrus at the University of North Carolina-Chapel Hill for advice and critical reading of the manuscript. This work was supported by NSF grant BE/GenEn-0412599.

\section{LITERATURE CITED}

Allen, C., Reverchon, S., and Robert-Baudouy, J. 1989. Nucleotide sequence of the Erwinia chrysanthemi gene encoding 2-keto-3-deoxygluconate permease. Gene 83:233-241.

Altschul, S. F., Gish, W., Miller, W., Myers, E. W., and Lipman, D. J. 1990. Basic local alignment search tool. J. Mol. Biol. 215:403-410.

Baker, C. S., Morozov, I., Suzuki, K., Romeo, T., and Babitzke, P. 2002. CsrA regulates glycogen biosynthesis by preventing translation of $g l g C$ in Escherichia coli. Mol. Microbiol. 44:1599-1610.

Barnard, A. M., and Salmond, G. P. 2007. Quorum sensing in Erwinia species. Anal. Bioanal. Chem. 387:415-423.

Barnard, A. M., Bowden, S. D., Burr, T., Coulthurst, S. J., Monson, R. E., and Salmond, G. P. 2007. Quorum sensing, virulence and secondary metabolite production in plant soft-rotting bacteria. Philos. Trans. R. Soc. Lond. B Biol. Sci. 362:1165-1183.

Boch, J., Joardar, V., Gao, L., Robertson, T. L., Lim, M., and Kunkel, B. N. 2002. Identification of Pseudomonas syringae pv. tomato genes induced during infection of Arabidopsis thaliana. Mol. Microbiol. 44:7388 .

Chang, J. H., Urbach, J. M., Law, T. F., Arnold, L. W., Hu, A., Gombar, S., Grant, S. R., Ausubel, F. M., and Dangl, J. L. 2005. A high-throughput, near-saturating screen for type III effector genes from Pseudomonas syringae. Proc. Natl. Acad. Sci. U.S.A. 102:2549-2554.

Charkowski, A. O. 2009. Decaying signals: Will understanding bacterialplant communications lead to control of soft rot? Curr. Opin. Biotechnol. 20:178-184.

Chatterjee, A., Cui, Y., Liu, Y., Dumenyo, C. K., and Chatterjee, A. K. 1995. Inactivation of rsmA leads to overproduction of extracellular pectinases, cellulases, and proteases in Erwinia carotovora subsp. carotovora in the absence of the starvation/cell density-sensing signal, N-(3-oxohexanoyl)L-homoserine lactone. Appl. Environ. Microbiol. 61:1959-1967.

Chatterjee, A., Cui, Y., and Chatterjee, A. K. 2002. Regulation of Erwinia carotovora $h r p L_{E c c}\left(\right.$ sigma- $L_{E c c}$ ), which encodes an extracytoplasmic function subfamily of sigma factor required for expression of the HRP regulon. Mol. Plant-Microbe Interact. 15:971-980. 
Chatterjee, A., Cui, Y., Yang, H., Collmer, A., Alfano, J. R., and Chatterjee, A. K. 2003. GacA, the response regulator of a two-component system, acts as a master regulator in Pseudomonas syringae pv. tomato DC3000 by controlling regulatory RNA, transcriptional activators, and alternate sigma factors. Mol. Plant-Microbe Interact. 16:1106-1117.

Chatterjee, A., Cui, Y., and Chatterjee, A. K. 2009. RsmC of Erwinia carotovora subsp. carotovora negatively controls motility, extracellular protein production, and virulence by binding FlhD and modulating transcriptional activity of the master regulator, FlhDC. J. Bacteriol. 191:4582-4593.

Cui, Y., Chatterjee, A., Liu, Y., Dumenyo, C. K., and Chatterjee, A. K. 1995. Identification of a global repressor gene, rsmA, of Erwinia carotovora subsp. carotovora that controls extracellular enzymes, $\mathrm{N}$-(3-oxohexanoyl)-L-homoserine lactone, and pathogenicity in soft-rotting $\mathrm{Er}$ winia spp. J. Bacteriol. 177:5108-5115.

Cui, Y., Madi, L., Mukherjee, A., Dumenyo, C. K., and Chatterjee, A. K. 1996. The RsmA- mutants of Erwinia carotovora subsp. carotovora strain Ecc71 overexpress $h r p N_{E c c}$ and elicit a hypersensitive reactionlike response in tobacco leaves. Mol. Plant-Microbe Interact. 9:565573.

Cui, Y., Mukherjee, A., Dumenyo, C. K., Liu, Y., and Chatterjee, A. K. 1999. rsmC of the soft-rotting bacterium Erwinia carotovora subsp. carotovora negatively controls extracellular enzyme and harpin ${ }_{\mathrm{Ecc}}$ production and virulence by modulating levels of regulatory RNA $(r s m B)$ and RNA-binding protein (RsmA). J. Bacteriol. 181:6042-6052.

Cui, Y., Chatterjee, A., Hasegawa, H., Dixit, V., Leigh, N., and Chatterjee, A. K. 2005. ExpR, a LuxR homolog of Erwinia carotovora subsp. carotovora, activates transcription of $r s m A$, which specifies a global regulatory RNA-binding protein. J. Bacteriol. 187:4792-4803.

Cui, Y., Chatterjee, A., Hasegawa, H., and Chatterjee, A. K. 2006. Erwinia carotovora subspecies produce duplicate variants of ExpR, LuxR homologs that activate rsmA transcription but differ in their interactions with N-acylhomoserine lactone signals. J. Bacteriol. 188:4715-4726.

Cui, Y., Chatterjee, A., Yang, H., and Chatterjee, A. K. 2008. Regulatory network controlling extracellular proteins in Erwinia carotovora subsp. carotovora: FlhDC, the master regulator of flagellar genes, activates $r s m B$ regulatory RNA production by affecting gacA and hexA ( $r h A)$ expression. J. Bacteriol. 190:4610-4623.

Datsenko, K. A., and Wanner, B. L. 2000. One-step inactivation of chromosomal genes in Escherichia coli K-12 using PCR products. Proc. Natl. Acad. Sci. U.S.A. 97:6640-6645.

de Souza, J. T., Mazzola, M., and Raaijmakers, J. M. 2003. Conservation of the response regulator gene gacA in Pseudomonas species. Environ. Microbiol. 5:1328-1340.

Dong, X. 2004. NPR1, all things considered. Curr. Opin. Plant Biol. 7:547-552.

Eisenberg, R. C., and Dobrogosz, W. J. 1967. Gluconate metabolism in Escherichia coli. J. Bacteriol. 93:941-949.

Flego, D., Marits, R., Eriksson, A. R., Koiv, V., Karlsson, M. B., Heikinheimo, R., and Palva, E. T. 2000. A two-component regulatory system, pehR-pehS, controls endopolygalacturonase production and virulence in the plant pathogen Erwinia carotovora subsp. carotovora. Mol. Plant-Microbe Interact. 13:447-455

Glasner, J. D., Marquez-Villavicencio, M., Kim, H. S., Jahn, C. E., Ma, B., Biehl, B. S., Rissman, A. I., Mole, B., Yi, X., Yang, C. H., Dangl, J. L., Grant, S. R., Perna, N. T., and Charkowski, A. O. 2008. Niche-specificity and the variable fraction of the Pectobacterium pan-genome. Mol. Plant-Microbe Interact. 21:1549-1560.

Grant, S. R., Fisher, E. J., Chang, J. H., Mole, B. M., and Dangl, J. L. 2006. Subterfuge and manipulation: Type III effector proteins of phytopathogenic bacteria. Annu. Rev. Microbiol. 60:425-449.

Harris, S. J., Shih, Y. L., Bentley, S. D., and Salmond, G. P. 1998. The hexA gene of Erwinia carotovora encodes a LysR homologue and regulates motility and the expression of multiple virulence determinants. Mol. Microbiol. 28:705-717.

Harrison, M., Quinn, C., Ann Sells, I., and Graham, D. 1977. Waste potato dumps as sources of insects contaminated with soft rot coliform bacteria in relation to re-contamination of pathogen-free potato stocks. Potato Res. 20:37-52.

Horton, R. M., Hunt, H. D., Ho, S. N., Pullen, J. K., and Pease, L. R. 1989. Engineering hybrid genes without the use of restriction enzymes: Gene splicing by overlap extension. Gene 77:61-68.

Huelsenbeck, J. P., and Ronquist, F. 2001. MRBAYES: Bayesian inference of phylogenetic trees. Bioinformatics 17:754-755.

Hugouvieux-Cotte-Pattat, N., and Robert-Baudouy, J. 1987. Hexuronate catabolism in Erwinia chrysanthemi. J. Bacteriol. 169:1223-1231.

Kariola, T., Palomaki, T. A., Brader, G., and Palva, E. T. 2003. Erwinia carotovora subsp. carotovora and Erwinia-derived elicitors $\mathrm{HrpN}$ and PehA trigger distinct but interacting defense responses and cell death in Arabidopsis. Mol. Plant-Microbe Interact. 16:179-187.
Kitten, T., Kinscherf, T. G., McEvoy, J. L., and Willis, D. K. 1998. A newly identified regulator is required for virulence and toxin production in Pseudomonas syringae. Mol. Microbiol. 28:917-929.

Koek, M. M., Muilwijk, B., van der Werf, M. J., and Hankemeier, T. 2006. Microbial metabolomics with gas chromatography/mass spectrometry. Anal. Chem. 78:1272-1281.

Laasik, E., Andresen, L., and Mae, A. 2006. Type II quorum sensing regulates virulence in Erwinia carotovora ssp. carotovora. FEMS (Fed. Eur. Microbiol. Soc.) Microbiol. Lett. 258:227-234.

Lagaert, S., Belien, T., and Volckaert, G. 2009. Plant cell walls: Protecting the barrier from degradation by microbial enzymes. Semin. Cell Dev. Biol. 20:1064-1073.

Lazdunski, A. M., Ventre, I., and Sturgis, J. N. 2004. Regulatory circuits and communication in gram-negative bacteria. Nat. Rev. Microbiol. 2:581-592.

Leatham, M. P., Stevenson, S. J., Gauger, E. J., Krogfelt, K. A., Lins, J. J., Haddock, T. L., Autieri, S. M., Conway, T., and Cohen, P. S. 2005 Mouse intestine selects nonmotile flhDC mutants of Escherichia coli MG1655 with increased colonizing ability and better utilization of carbon sources. Infect. Immun. 73:8039-8049.

Li, Y., Peng, Q., Selimi, D., Wang, Q., Charkowski, A. O., Chen, X., and Yang, C. H. 2009. The plant phenolic compound p-coumaric acid represses gene expression in the Dickeya dadantii type III secretion system. Appl. Environ. Microbiol. 75:1223-1228.

Lindeberg, M., Stavrinides, J., Chang, J. H., Alfano, J. R., Collmer, A., Dangl, J. L., Greenberg, J. T., Mansfield, J. W., and Guttman, D. S. 2005. Proposed guidelines for a unified nomenclature and phylogenetic analysis of type III Hop effector proteins in the plant pathogen Pseudomonas syringae. Mol. Plant-Microbe Interact. 18:275-282.

Liu, H., Coulthurst, S. J., Pritchard, L., Hedley, P. E., Ravensdale, M., Humphris, S., Burr, T., Takle, G., Brurberg, M. B., Birch, P. R., Salmond, G. P., and Toth, I. K. 2008. Quorum sensing coordinates brute force and stealth modes of infection in the plant pathogen Pectobacterium atrosepticum. PLoS Pathog. 4:e1000093. Published online.

Liu, Y., Cui, Y., Mukherjee, A., and Chatterjee, A. K. 1998. Characterization of a novel RNA regulator of Erwinia carotovora ssp. carotovora that controls production of extracellular enzymes and secondary metabolites. Mol. Microbiol. 29:219-234.

Liu, Y., Jiang, G., Cui, Y., Mukherjee, A., Ma, W. L., and Chatterjee, A. K. 1999. $k d g R_{E c c}$ negatively regulates genes for pectinases, cellulase, protease, Harpin ${ }_{\mathrm{Ecc}}$, and a global RNA regulator in Erwinia carotovora subsp. carotovora. J. Bacteriol. 181:2411-2421.

Matsumoto, H., Jitareerat, P., Baba, Y., and Tsuyumu, S. 2003. Comparative study of regulatory mechanisms for pectinase production by $\mathrm{Er}$ winia carotovora subsp. carotovora and Erwinia chrysanthemi. Mol. Plant-Microbe Interact. 16:226-237.

McCarter-Zorner, N. J., Franc, G. D., Harrison, M. D., Michaud, J. E., Quinn, C. E., Sells, I. A., and Graham, D. C. 1984. Soft rot Erwinia in surface and underground waters in Southern Scotland and in Colorado, United States. J. Appl. Bacteriol. 57:95-105.

McCarter-Zorner, N. J., Harrison, M. D., Franc, G. D., Quinn, C. E., Sells, I. A., and Graham, D. C. 1985. Soft rot Erwinia bacteria in the rhizosphere of weeds and crop plants in Colorado, United States and Scotland. J. Appl. Bacteriol. 59:357-368.

Miriagou, V., Carattoli, A., Tzelepi, E., Villa, L., and Tzouvelekis, L. S. 2005. IS26-associated In4-type integrons forming multiresistance loci in enterobacterial plasmids. Antimicrob. Agents Chemother. 49:35413543.

Mole, B. M., Baltrus, D. A., Dangl, J. L., and Grant, S. R. 2007. Global virulence regulation networks in phytopathogenic bacteria. Trends Microbiol. 15:363-371.

Molina, J. M., Harrison, D., and Brewer, J. W. 1974. Transmission of Erwinia carotovora var. atroseptica by Drosophila melanogaster Meig. I. Acquisition and transmission of the bacterium. Am. Potato J. 51:245250.

Mukherjee, A., Cui, Y., Ma, W., Liu, Y., Ishihama, A., Eisenstark, A., and Chatterjee, A. K. 1998. RpoS (sigma-S) controls expression of $r s m A$, a global regulator of secondary metabolites, harpin, and extracellular proteins in Erwinia carotovora. J. Bacteriol. 180:3629-3634.

Mukherjee, A., Cui, Y., Ma, W., Liu, Y., and Chatterjee, A. K. 2000. hexA of Erwinia carotovora ssp. carotovora strain Ecc71 negatively regulates production of RpoS and $r s m B$ RNA, a global regulator of extracellular proteins, plant virulence and the quorum-sensing signal, $\mathrm{N}$-(3-oxohexanoyl)-L-homoserine lactone. Environ. Microbiol. 2:203-215.

Murata, H., Chatterjee, A., Liu, Y., and Chatterjee, A. K. 1994. Regulation of the production of extracellular pectinase, cellulase, and protease in the soft rot bacterium Erwinia carotovora subsp. carotovora: Evidence that aepH of E. carotovora subsp. carotovora 71 activates gene expression in E. carotovora subsp. carotovora, E. carotovora subsp. atroseptica, and Escherichia coli. Appl. Environ. Microbiol. 60:3150-3159. 
Murray, E. L., and Conway, T. 2005. Multiple regulators control expression of the Entner-Doudoroff aldolase (Eda) of Escherichia coli. J. Bacteriol. 187:991-1000.

Nasser, W., Condemine, G., Plantier, R., Anker, D., and Robert-Baudouy, J. 1991. Inducing properties of analogs of 2-keto-3-deoxygluconate on the expression of pectinase genes of Erwinia chrysanthemi. FEMS (Fed. Eur. Microbiol. Soc.) Microbiol. Lett. 65:73-78.

Nasser, W., Robert-Baudouy, J., and Reverchon, S. 1997. Antagonistic effect of CRP and $\mathrm{KdgR}$ in the transcription control of the Erwinia chrysanthemi pectinolysis genes. Mol. Microbiol. 26:1071-1082.

Pirhonen, M., Flego, D., Heikinheimo, R., and Palva, E. T. 1993. A small diffusible signal molecule is responsible for the global control of virulence and exoenzyme production in the plant pathogen Erwinia carotovora. EMBO (Eur. Mol. Biol. Organ.) J. 12:2467-2476.

Pouyssegur, J., and Stoeber, F. 1974. Genetic control of the 2-keto-3-deoxy-d-gluconate metabolism in Escherichia coli $\mathrm{K}-12$ : $k d g$ regulon. J. Bacteriol. 117:641-651.

Pruss, B. M., Campbell, J. W., Van Dyk, T. K., Zhu, C., Kogan, Y., and Matsumura, P. 2003. FlhD/FlhC is a regulator of anaerobic respiration and the Entner-Doudoroff pathway through induction of the methylaccepting chemotaxis protein Aer. J. Bacteriol. 185:534-543.

Pruss, B. M., Besemann, C., Denton, A., and Wolfe, A. J. 2006. A complex transcription network controls the early stages of biofilm development by Escherichia coli. J. Bacteriol. 188:3731-3739.

Rashid, M. H., and Kornberg, A. 2000. Inorganic polyphosphate is needed for swimming, swarming, and twitching motilities of Pseudomonas aeruginosa. Proc. Natl. Acad. Sci. U.S.A. 97:4885-4890.

Rico, A., and Preston, G. M. 2008. Pseudomonas syringae pv. tomato DC3000 uses constitutive and apoplast-induced nutrient assimilation pathways to catabolize nutrients that are abundant in the tomato apoplast. Mol. Plant-Microbe Interact. 21:269-282.

Rodionov, D. A., Gelfand, M. S., and Hugouvieux-Cotte-Pattat, N. 2004 Comparative genomics of the KdgR regulon in Erwinia chrysanthemi 3937 and other gamma-proteobacteria. Microbiology 150:3571-3590.

Rudd, K. E. 1998. Linkage map of Escherichia coli K-12, edition 10: The physical map. Microbiol. Mol. Biol. Rev. 62:985-1019.
Ruijter, G. D. G., and Visser, J. 1996. Determination of intermediary metabolites in Aspergillus niger. J. Microbiol. Methods 25:295-302.

Sambrook, J., and Russell, D. W. 2001. Molecular Cloning. Cold Spring Harbor Laboratory Press, Cold Spring Harbor, NY, U.S.A

Sjoblom, S., Brader, G., Koch, G., and Palva, E. T. 2006. Cooperation of two distinct ExpR regulators controls quorum sensing specificity and virulence in the plant pathogen Erwinia carotovora. Mol. Microbiol. 60:1474-1489.

Smith, T. G., and Hoover, T. R. 2009. Deciphering bacterial flagellar gene regulatory networks in the genomic era. Adv. Appl. Microbiol. 67:257 295.

Takle, G. W., Toth, I. K., and Brurberg, M. B. 2007. Evaluation of reference genes for real-time RT-PCR expression studies in the plant pathogen Pectobacterium atrosepticum. BMC Plant Biol. 7:50.

Toth, I. K., and Birch, P. R. 2005. Rotting softly and stealthily. Curr. Opin. Plant Biol. 8:424-429.

Truesdell, S. J., Sims, J. C., Boerman, P. A., Seymour, J. L., and Lazarus, R. A. 1991. Pathways for metabolism of ketoaldonic acids in an $\mathrm{Er}$ winia sp. J. Bacteriol. 173:6651-6656.

Whitehead, N. A., Byers, J. T., Commander, P., Corbett, M. J., Coulthurst, S. J., Everson, L., Harris, A. K., Pemberton, C. L., Simpson, N. J. Slater, H., Smith, D. S., Welch, M., Williamson, N., and Salmond, G. P. 2002. The regulation of virulence in phytopathogenic Erwinia species: Quorum sensing, antibiotics and ecological considerations. Antonie Leeuwenhoek 81:223-231.

Yang, S., Peng, Q., San Francisco, M., Wang, Y., Zeng, Q., and Yang, C. H 2008. Type III secretion system genes of Dickeya dadantii 3937 are induced by plant phenolic acids. PLoS One 3:e2973. Published online.

Yap, M. N., Barak, J. D., and Charkowski, A. O. 2004. Genomic diversity of Erwinia carotovora subsp. carotovora and its correlation with virulence. Appl. Environ. Microbiol. 70:3013-3023.

Zienkiewicz, M., Kern-Zdanowicz, I., Golebiewski, M., Zylinska, J., Mieczkowski, P., Gniadkowski, M., Bardowski, J., and Ceglowski, P. 2007. Mosaic structure of p1658/97, a 125-kilobase plasmid harboring an active amplicon with the extended-spectrum beta-lactamase gene blaSHV-5. Antimicrob. Agents Chemother. 51:1164-1171. 